\title{
CARACTERÍSTICAS FÍSICAS DE UM LATOSSOLO VERMELHO-ESCURO NO CERRADO DE PLANALTINA, DF, SUBMETIDO À AÇÃO DO FOGO1
}

\author{
SILVIO TULIO SPERA ${ }^{2}$, ADRIANA REATTO ${ }^{3}$, JOÃO ROBERTO CORREIA ${ }^{3}$ e JOSÉ CARLOS SOUSA SILVA ${ }^{4}$
}

\begin{abstract}
RESUMO - Os principais efeitos do fogo como manejo de solo estão relacionados a alterações biológicas e químicas do solo. A queima pode ainda alterar a umidade do solo em razão de mudanças na taxa de infiltração, na taxa de transpiração, na porosidade e na repelência do solo à água. O objetivo deste trabalho foi avaliar as características físicas de um Latossolo Vermelho-Escuro muito argiloso, plano, fase campo cerrado, submetido à ação do fogo, após ser utilizado durante 20 anos em pastagem nativa sem queima. Uma área de 1,25 ha foi submetida à ação bienal do fogo, e uma área adjacente, do mesmo tamanho, foi mantida protegida da ação do fogo. Após seis anos, não houve variações marcantes nas características físicas do solo induzidas pelo fogo, exceto no aumento da umidade do solo nas parcelas não queimadas. Nas parcelas onde se aplicou o fogo, observou-se tendência para o aumento da microporosidade, que pode ser atribuída à compactação promovida pelo impacto das gotas de chuva no solo desnudado pelo fogo. Conclui-se, entretanto, que a queima bienal não foi suficiente para provocar degradação no período estudado.
\end{abstract}

Termos para indexação: queimada, densidade do solo, retenção de água no solo, porosidade, teor de umidade.

\author{
PHYSICAL CHARACTERISTICS OF A DARK-RED LATOSOL (OXISOL) \\ OF THE BRAZILIAN SAVANNAS (“CERRADOS”) OF PLANALTINA UNDER FIRE ACTION
}

\begin{abstract}
The main effects of fire on the soil are related to biological and chemical alterations. Fire can also change the soil moisture as a consequence of alterations in infiltration rates, transpiration rates, porosity, and water repellence. The objective of this work was to evaluate physical characteristics of a heavy clayer Dark Red Latosol (Oxisol) submitted to fire treatments. The selected area of restrict sense Cerrado covers 2.5 ha which have been protected against fire since 1979, despite its use as native pasture during 20 years. The area was divided into two, half of it protected against fire and the other half submitted to fire every two years. Fire has caused no large variations on the physical characteristics of the soil. The non-burnt area has presented an increase on soil moisture. A slight increase of microporosity appeared on the burnt area throughout the period. This could be caused by the rain drops action against the bare soil. Fire every two years was not enough to cause significant degradation on the soil.
\end{abstract}

Index terms: burning, soil density, soil water retention, porosity, moisture content.

\footnotetext{
${ }^{1}$ Aceito para publicação em 9 de dezembro de 1999.

${ }^{2}$ Eng. Agrôn., M.Sc., Embrapa-Centro Nacional de Pesquisa de Trigo (CNPT), Caixa Postal 451, CEP 99001-970 Passo Fundo, RS. E-mail: spera@cnpt.embrapa.br

${ }^{3}$ Eng. Agrôn., M.Sc., Embrapa-Centro de Pesquisa Agropecuária dos Cerrados (CPAC), Caixa Postal 08223, CEP 73301-970 Planaltina, DF. E-mail: reatto@cpac.embrapa.br, jroberto@cpac.embrapa.br

${ }^{4}$ Biólogo, Ph.D., Embrapa-CPAC.

E-mail: jcarlos@cpac.embrapa.br
}

\section{INTRODUÇÃO}

A ação do fogo provoca uma série de modificações de natureza física, química e biológica no solo. Muitos autores referem-se ao uso do fogo como método de manejo de solo condenável, atribuindo-lhe possíveis ações degradantes e esterilizantes do solo. O fogo como modificador de ecossistemas tem estado em evidência nos últimos anos, principalmente 
por ser considerado uma das causas do aumento da concentração de gás carbônico na atmosfera. No Cerrado, esse elemento apresenta alta frequiência, com uma série de efeitos observados principalmente em relação à temperatura do solo e do ar, à umidade e a nutrientes, a estratégias da flora, à produtividade primária e ao desenvolvimento das plantas (Meirelles, 1990).

Os principais efeitos do uso do fogo estão relacionados a alterações biológicas e químicas, tais como redução ou alteração da população microbiana, aumento temporário da disponibilidade de nutrientes, alteração no pH, aumento da fonte de carbono e oxidação da matéria orgânica (Santos et al., 1992). Entretanto, não foram observadas alterações nos teores de matéria orgânica e nos valores de CTC de um Latossolo Vermelho-Amarelo variação Una, distrófico, sob pastagem nativa de Cerrado em Minas Gerais, nas camadas abaixo de $3 \mathrm{~cm}$ de profundidade (Araújo et al., 1994).

Apesar disso, a queima pode alterar a umidade do solo, em razão de mudanças na taxa de infiltração, na taxa de transpiração, na porosidade e na repelência do solo à água. De acordo com estudos realizados em Latossolo Amarelo do Vale do Ribeira, Estado de São Paulo, a queima promove a formação de crosta superficial, que reduz a infiltração da água no solo (Hernani et al., 1987). A redução da porosidade também é observada. Porém, Meirelles (1990) não constatou diferenças significativas no teor de umidade entre áreas queimadas e não-queimadas de uma gleba de campo sujo de Cerrado, em Planaltina, DF. Leite (1996) verificou, um mês após a queima, aumento na infiltração de água em um Latossolo VermelhoAmarelo. Sharrow \& Wright (1977) constataram redução na infiltração e no armazenamento da água em solo argiloso, nos Estados Unidos, sob pastagem nativa, quando submetida à queima com gasolina.

Mallik et al. (1984) observaram, em um solo Podzólico Bruno, em clima temperado, o entupimento dos poros da camada superficial pelas cinzas oriundas de queimadas. Hernani et al. (1987), entretanto, não verificaram esse efeito em solo em clima tropical (Latossolo Amarelo), embora Santos et al. (1992) tivessem verificado, em Latossolo Vermelho-Amarelo, que a umidade do solo sob pastagem não queimada é o dobro da submetida à queima, e atribuíram essa diferença ao entupimento dos poros do solo pelas cinzas. Meirelles (1990) não observou, nas diferentes profundidades de um Latossolo VermelhoAmarelo de textura média sob Cerrado, nenhuma diferença significativa entre as áreas queimadas e áreas não-queimadas, quanto à umidade do solo. O mesmo foi verificado por Lloyd (1972), em um solo argiloso cascalhento raso.

A mesofauna do solo do Cerrado, constituída principalmente por microartrópodos e oligoquetos, desempenha a importante função de movimentar os poros do solo nas fissuras e nas interfaces entre a serapilheira e o solo. A ação indiscriminada do fogo diminui a quantidade de material orgânico, fonte energética dos microrganismos, que, assim, culmina na diminuição da população da mesofauna e conseqüentemente na perda da capacidade produtiva do solo (Assad, 1996).

O Cerrado, como um tipo de savana, tem como determinantes a umidade do solo, o conteúdo nutricional, a herbivoria e o solo (Frost et al., 1986; Ramos \& Rosa, 1996). No caso do fogo, sua ação no estrato herbáceo-subarbustivo do cerrado resulta na rápida mineralização e na acelerada ciclagem dos nutrientes. Já no tocante ao estrato arbóreo, o fogo influencia principalmente a redução do porte das árvores e o aumento da sua tortuosidade (Ramos \& Rosa, 1996).

O objetivo deste trabalho foi verificar as alterações das características físicas de um Latossolo Vermelho-Escuro, textura muito argilosa, em relevo praticamente plano, sob Cerrado Ralo, submetido a sete anos de tratamento com fogo e sem fogo bianual.

\section{MATERIAL E MÉTODOS}

A área de estudo está localizada a nordeste do Distrito Federal, próximo a Planaltina, DF, dentro da área experimental da Embrapa-Centro de Pesquisa Agropecuária dos Cerrados, nas coordenadas $15^{\circ} 38^{\prime} \mathrm{S}$ e $47^{\circ} 43^{\prime} \mathrm{W}$ (datum horizontal Córrego Alegre, MG), cerca de $25 \mathrm{~km}$ a nordeste de Brasília, DF. O Cerrado Ralo é uma subdivisão do Cerrado em sentido restrito. É um tipo de vegetação arbóreo-arbustiva, com a cobertura arbórea de 5\% a $20 \%$ e altura média de $2 \mathrm{~m}$ a $3 \mathrm{~m}$. Representa a forma mais baixa e menos densa do Cerrado sentido restrito. $\mathrm{O}$ estrato arbustivo-herbáceo é mais destacado que nos outros 
subtipos de Cerrado em sentido restrito (Ribeiro \& Walter, 1998).

De acordo com dados provenientes da estação climática localizada a $2 \mathrm{~km}$ da área de estudo, o clima pode ser caracterizado como Aw na classificação de Köppen, apresentando uma estação seca de cinco meses, com precipitação média anual de $1.577 \mathrm{~mm}$, temperatura média anual de $20,4^{\circ} \mathrm{C}$, temperatura máxima média de $26,6^{\circ} \mathrm{C}$, e mínima média de $15,8^{\circ} \mathrm{C}$, com altitude de $1.100 \mathrm{~m}$. Na Tabela 1 , estão apresentados os dados climatológicos de 1987 a 1994, período este, no qual foram conduzidos os ensaios.

A classe de solo da área de estudo, de acordo com Embrapa (1978), é o Latossolo Vermelho-Escuro álico A moderado, textura muito argilosa, relevo plano a suaveondulado, fase cerrado (Typic haplustox), desenvolvido a partir da decomposição da cobertura detrítico-laterítica de caráter argiloso do Terciário. Essa classe ocupa 18,6\% da área do Cerrado (Reatto et al., 1998).

Uma área de 1,25 ha, sem fogo desde 1979, foi submetida à ação bienal do fogo, e uma área adjacente, do mesmo tamanho, foi mantida protegida da ação dele. Cada área foi dividida em dois blocos. Amostras deformadas e indeformadas foram coletadas em uma transecção de cem metros dentro de cada bloco, num total de quinze pontos de amostragem por transecção, nas profundidades de 0 a $5 \mathrm{~cm}, 5$ a $10 \mathrm{~cm}$ e 10 a $20 \mathrm{~cm}$. Foram utilizados anéis volumétricos de $100 \mathrm{~cm}^{3}$. A densidade do solo e a porosidade total foram obtidas de acordo com Embrapa (1997); a curva de retenção de água do solo nas tensões 0,006, 0,01, 0,033, 0,06, 0,1 e 1,5 MPa foram determinadas pelo método da centrífuga, adaptado por Freitas Júnior \& Silva (1984). O carbono orgânico foi determinado pelo método descrito em Embrapa (1997). A capacidade de água disponível foi calculada pela fórmula $\mathrm{CAD}=\left[(\mathrm{CC}-\mathrm{PMP}) \cdot 10^{-1}\right] . \mathrm{Dg} \cdot \mathrm{h}$, onde CAD é a capacidade de água disponível, CC é a umidade na capacidade de campo (0,033 MPa), PMP é a umi- dade no ponto de murchamento permanente (1,5 MPa), Dg é a densidade do solo $\left(\mathrm{g} \mathrm{cm}^{-3}\right)$ e h é a espessura da camada de solo estudada $(\mathrm{cm})$, conforme Buchele \& Silva (1992). A análise granulométrica e a de argila dispersa em água foram feitas de acordo com Embrapa (1997).

As classes de porosidade do solo foram definidas conforme sugestão de Luxmoore (1981), e os poros foram divididos em três classes de tamanho: microporos (poros $<3 \mu \mathrm{m}$ ), mesoporos (poros $<30 \mu \mathrm{m}$ e $\geq 3 \mu \mathrm{m}$ ), maiores responsáveis pelo armazenamento de água disponível, e macroporos (poros $\geq 30 \mathrm{~mm}$ ). A determinação dessas classes foi feita pelo uso da fórmula da relação entre diâmetro do poro e tensão da água retida em tubos capilares (fenômeno da capilaridade):

$\mathrm{h}=(2 \tau \cos \alpha) \cdot(g \rho r)^{-1}$,

onde h é a altura de ascensão da água no tubo capilar, $\rho=$ densidade da água; $g=$ aceleração da gravidade; $\mathrm{r}=$ raio do tubo capilar; $\alpha=$ ângulo de contato do líquido com as paredes do capilar; e $\tau=$ tensão superficial da água, aplicada aos dados resultantes da curva de retenção de água do solo (Hillel, 1980; Ferreira, 1993).

As avaliações foram iniciadas em 1988, quando foram coletadas as amostras antes da aplicação do fogo. A partir desse ano, a cada dois anos, foram retiradas amostras e aplicado o fogo logo em seguida, até as últimas amostragens em 1994. Os contrastes entre as médias foram comparados pelo teste $t$, conforme sugestão de Banzatto \& Kronka (1992).

\section{RESULTADOS E DISCUSSÃO}

Os resultados médios da análise granulométrica realizados em 1994 nas áreas estudadas são apresentados na Tabela 2. Nota-se que os teores de areia grossa e os de areia fina não diferem significativamente. Os menores teores de silte e os maiores de argila nas

TABELA 1. Dados climatológicos do período de 1987 a 1994, referentes às médias de temperatura máxima absoluta (TM), mínima absoluta (TN), compensada anual (TX), umidade relativa do ar (UR) e total de precipitação anual (PP).

\begin{tabular}{lcccccccc}
\hline Parâmetro & \multicolumn{7}{c}{ Ano } \\
\cline { 2 - 8 } & 1987 & 1988 & 1989 & 1990 & 1991 & 1992 & 1993 & 1994 \\
\hline TM $\left({ }^{\circ} \mathrm{C}\right)$ & 28,4 & 28,1 & 27,5 & 28,0 & 27,5 & 26,9 & 28,4 & 28,5 \\
TN $\left({ }^{\circ} \mathrm{C}\right)$ & 16,3 & 15,7 & 16,6 & 16,6 & 15,9 & 15,6 & 15,6 & 17,0 \\
TX $\left({ }^{\circ} \mathrm{C}\right)$ & 22,3 & 22,0 & 22,1 & 22,3 & 21,9 & 21,3 & 22,0 & 22,7 \\
UR $(\%)$ & 67,8 & 68,1 & 69,7 & 70,3 & 69,3 & 72,0 & 68,2 & 65,5 \\
PP $(\mathrm{mm})$ & 1210,7 & 1675,9 & 1641,4 & 1254,2 & 1798,7 & 1884,6 & 1110,3 & 1175,9 \\
\hline
\end{tabular}

Fonte: Estação climatológica da Embrapa-Centro de Pesquisa Agropecuária dos Cerrados, Planaltina, DF. 
parcelas submetidas ao fogo diferem significativamente e podem ser atribuídos a fatores genéticos do solo, uma vez que as parcelas não queimadas estão mais próximas da borda da chapada. Macedo \& Bryant (1987) encontraram numa toposseqüência de Latossolos de chapadas, no Distrito Federal, redução discreta nos teores de argila do solo, do centro para a borda da chapada. Essas diferenças entre os teores de silte e de argila, entretanto, não alteraram as demais características.

Deve-se considerar também que valores de desvio-padrão de média, que resultam em coeficientes de variação maiores que $30 \%$, o que é considerado muito alto, são comumente encontrados quando se analisam estatisticamente solos de Cerrado (PimentelGomes, 1984).

Quanto à capacidade de água disponível nas camadas de 0 a $5 \mathrm{~cm}, 5$ a $10 \mathrm{~cm}$ e 10 a $20 \mathrm{~cm}$ (Tabela 3), não foram verificadas diferenças significativas nem entre as médias dos anos, nem entre os tratamentos.

Mallik et al. (1984) observaram que a redução da capacidade de retenção de água pelo solo pode ser atribuída à diminuição na microporosidade, atributo esse que pode variar conforme as alterações na densidade do solo (Archer \& Smith, 1972). Nas parcelas onde se aplicou o fogo, constatou-se, no período do estudo, tendência estatisticamente não-significativa de aumento da densidade do solo no ano de 1994 Esse aumento na parcela com fogo pode ser atribuído à compactação promovida pelo impacto das gotas de chuva no solo desnudado pelo fogo e à umidade mais baixa, que conduziu à maior compactação, em decorrência do ressecamento do solo, conforme observaram Hernani et al. (1987). Em 1991 e 1992, constatou-se alta pluviosidade, enquanto 1994 foi mais seco. Isso pode ser observado na Tabela 1. Leite (1996), entretanto, não constatou alteração na densidade do solo, após um ano da queima, em campo cerrado do Distrito Federal, nesse período.

Observa-se, pelos dados da Tabela 3, que a capacidade de água disponível diminui à medida que aumenta a densidade do solo, concordando com Archer \& Smith (1972).

O volume total de poros e a macroporosidade (Tabelas 3 e 4) mostraram, durante o período, nas parcelas submetidas ao fogo, maiores variações, mantendo-se praticamente estabilizados nas parcelas sem fogo durante o período. $\mathrm{O}$ mesmo comportamento foi observado na mesoporosidade (Tabela 4). A microporosidade nas parcelas com fogo foi significativamente menor que naquelas sem fogo, nas camadas de 0 a $5 \mathrm{~cm}$ e 5 a $10 \mathrm{~cm}$. Isso, porém, não alterou significativamente os teores de água disponível, mostrando, assim, que essa característica não depende da microporosidade, mas da mesoporosidade. Verifica-se, em 1992, após dois anos de chuvas pesadas, aumento não-significativo na densidade do solo, com reflexos na porosidade total do solo, havendo acréscimo na microporosidade e redução na macroporosidade. Em 1994, esses valores voltam ao normal, provavelmente devido à atividade biológica.

Os teores de carbono orgânico do solo, nas camadas estudadas, praticamente não variaram entre as parcelas com fogo e sem fogo, nas diferentes profundidades. A variação bienal do carbono orgânico

TABELA 2. Médias (X) e desvio-padrão (s), em $\mathrm{g} \mathrm{kg}^{-1}$, dos resultados da análise granulométrica do Latossolo Vermelho-Escuro, realizada em 1994, em diferentes profundidades, nas parcelas submetidas ou não à queima com fogo.

\begin{tabular}{|c|c|c|c|c|c|c|c|c|c|}
\hline \multirow{2}{*}{$\begin{array}{l}\text { Trata- } \\
\text { mento }\end{array}$} & \multirow{2}{*}{$\begin{array}{l}\text { Profun- } \\
\text { didade } \\
(\mathrm{cm})\end{array}$} & \multicolumn{2}{|c|}{ Areia grossa } & \multicolumn{2}{|c|}{ Areia fina } & \multicolumn{2}{|c|}{ Silte } & \multicolumn{2}{|c|}{ Argila } \\
\hline & & $\mathrm{X}$ & $\mathrm{s}$ & $X$ & $\mathrm{~s}$ & $\mathrm{X}$ & $\mathrm{s}$ & $\mathrm{X}$ & $\mathrm{s}$ \\
\hline \multirow[t]{3}{*}{ Com fogo } & $0-5$ & 22 & 5,9 & 279 & 9,0 & $116^{* *}$ & 24,7 & $583 * *$ & 29,8 \\
\hline & $5-10$ & 23 & 5,8 & 273 & 5,8 & $114 * *$ & 25,2 & $590 * *$ & 30,0 \\
\hline & $10-20$ & 25 & 5,0 & 262 & 10,4 & $108 * *$ & 25,2 & $605 * *$ & 31,2 \\
\hline \multirow[t]{3}{*}{ Sem fogo } & $0-5$ & 24 & 7,2 & 271 & 17,1 & $155^{* *}$ & 18,6 & $550 * *$ & 29,8 \\
\hline & $5-10$ & 23 & 5,8 & 263 & 15,3 & $153 * *$ & 15,3 & $561 * *$ & 26,5 \\
\hline & $10-20$ & 22 & 2,9 & 248 & 15,3 & $150 * *$ & 8,7 & $580 * *$ & 22,9 \\
\hline
\end{tabular}

** As médias dos tratamentos com fogo e sem fogo, nas suas respectivas profundidades, diferem entre si a $1 \%$ de probabilidade, pelo teste t. 
(Tabela 5) não foi significativa e não se verificaram indícios de perdas de carbono orgânico por percolação ou erosão, conforme constatado por Araújo et al. (1994). Os valores referentes a carbono orgânico, principalmente na camada de 0 a 5 cm, não diferem entre si pelo teste $t$; entretanto, esses valores nas parcelas com fogo são sempre maiores que na parcela sem fogo, e, de acordo com Santos et al. (1992), a queima de vegetação nativa rala leva ao aumento da fonte de carbono no solo. Esse aumento de carbono orgânico, ainda que não significativo na parcela com fogo, pode ser atribuído à deposição de cinzas no solo pela queima da vegetação. Comparando-se os valores da Tabela 1 com os da Tabela 5, verifica-se que o aumento nos conteúdos de carbono orgânico no solo coincide com o aumento dos índices pluviométricos no período, indicando que maiores volumes de biomassa produzidos pelo ex- cesso de chuvas podem resultar em maiores quantidades de carbono orgânico adicionado ao solo pelas queimadas.

Os dados referentes a argila dispersa em água são disponíveis apenas em relação ao ano de 1994; não foram feitas avaliações em todo o período estudado nesse ano. A argila dispersa em água, de ambas as parcelas, em 1994, é estatisticamente igual para as respectivas profundidades (Tabela 6), não podendo a argila dispersa, nesse caso, ser apontada como causa de entupimento de microporos, diferentemente do que observaram Mallik et al. (1984).

De acordo com Santos et al. (1992), as perdas de solo e de matéria orgânica em pastagens queimadas são maiores quanto menor o intervalo entre queimas, a declividade do terreno e o tipo de solo. Por essa razão, a queima bienal não deve estar promovendo alterações significativas nas características físicas do solo.

TABELA 3. Médias (X) e desvio-padrão (s) da capacidade de água disponível $\left(\mathrm{mm} \mathrm{cm}^{-1}\right)$, da densidade do $\operatorname{solo}\left(\mathrm{g} \mathrm{dm}^{-3}\right)$ e do volume total de poros (\% em volume de solo), em diferentes profundidades, nas parcelas submetidas ou não à queima com fogo, no período de 1988 a 1994 1.

\begin{tabular}{|c|c|c|c|c|c|c|c|c|c|c|c|}
\hline \multirow{2}{*}{$\begin{array}{l}\text { Trata- } \\
\text { mento }\end{array}$} & \multirow{2}{*}{$\begin{array}{l}\text { Profun- } \\
\text { didade } \\
(\mathrm{cm})\end{array}$} & \multicolumn{2}{|c|}{1988} & \multicolumn{2}{|c|}{1990} & \multicolumn{2}{|c|}{1992} & \multicolumn{2}{|c|}{1994} & \multicolumn{2}{|c|}{ Média } \\
\hline & & $\mathrm{X}$ & $\mathrm{s}$ & $\mathrm{X}$ & $\mathrm{s}$ & $X$ & $\mathrm{~s}$ & $X$ & s & $X$ & $\mathrm{~s}$ \\
\hline & & \multicolumn{10}{|c|}{ Capacidade de água disponível $\left(\mathrm{mm} \mathrm{cm}^{-1}\right)$} \\
\hline \multirow[t]{3}{*}{ Com fogo } & $0-5$ & 1,13 & 0,08 & 1,02 & 0,12 & 0,97 & 0,12 & 1,15 & 0,11 & 1,07 & 0,12 \\
\hline & $5-10$ & 0,90 & 0,17 & 0,81 & 0,01 & 0,86 & 0,08 & 0,97 & 0,07 & 0,88 & 0,11 \\
\hline & $10-20$ & 0,84 & 0,18 & 0,83 & 0,08 & 0,85 & 0,07 & 0,87 & 0,04 & 0,85 & 0,09 \\
\hline \multirow[t]{4}{*}{ Sem fogo } & $0-5$ & 1,14 & 0,26 & 1,05 & 0,18 & 1,07 & 0,06 & 1,14 & 0,05 & 1,10 & 0,15 \\
\hline & $5-10$ & 0,91 & 0,08 & 0,86 & 0,05 & 0,93 & 0,06 & 0,94 & 0,06 & 0,91 & 0,06 \\
\hline & $10-20$ & 0,96 & 0,12 & 0,86 & 0,06 & 0,86 & 0,06 & 0,84 & 0,05 & 0,88 & 0,08 \\
\hline & & \multicolumn{10}{|c|}{ Densidade do solo $\left(\mathrm{g} \mathrm{dm}^{-3}\right)$} \\
\hline \multirow[t]{3}{*}{ Com fogo } & $0-5$ & 0,88 & 0,05 & 0,91 & 0,03 & 0,91 & 0,04 & 1,01 & 0,04 & 0,91 & 0,08 \\
\hline & $5-10$ & 0,84 & 0,01 & 0,80 & 0,05 & 0,87 & 0,08 & 0,97 & 0,07 & 0,87 & 0,08 \\
\hline & $10-20$ & 0,82 & 0,02 & 0,91 & 0,04 & 0,88 & 0,02 & 0,97 & 0,05 & 0,90 & 0,06 \\
\hline \multirow[t]{4}{*}{ Sem fogo } & $0-5$ & 0,85 & 0,07 & 0,92 & 0,02 & 0,96 & 0,03 & 0,93 & 0,08 & 0,92 & 0,06 \\
\hline & $5-10$ & 0,86 & 0,04 & 0,87 & 0,03 & 0,97 & 0,02 & 0,93 & 0,08 & 0,91 & 0,06 \\
\hline & $10-20$ & 0,83 & 0,01 & 0,92 & 0,04 & 0,92 & 0,03 & 0,92 & 0,05 & 0,90 & 0,05 \\
\hline & & \multicolumn{10}{|c|}{ Volume total de poros (\% em volume de solo) } \\
\hline \multirow[t]{3}{*}{ Com fogo } & $0-5$ & 57,28 & 2,03 & 61,08 & 1,04 & 60,86 & 1,28 & 64,04 & 1,00 & 60,89 & 2,67 \\
\hline & $5-10$ & 58,28 & 0,46 & 56,61 & 2,12 & 59,57 & 2,76 & 62,92 & 2,04 & 59,35 & 2,97 \\
\hline & $10-20$ & 57,79 & 0,61 & 60,86 & 1,28 & 59,92 & 0,75 & 62,94 & 1,47 & 60,38 & 2,14 \\
\hline \multirow[t]{3}{*}{ Sem fogo } & $0-5$ & 59,12 & 2,66 & 61,76 & 0,51 & 62,96 & 0,92 & 61,94 & 2,59 & 61,44 & 2,22 \\
\hline & $5-10$ & 59,60 & 1,29 & 59,97 & 1,19 & 63,15 & 0,64 & 61,82 & 2,53 & 61,14 & 2,01 \\
\hline & $10-20$ & 59,33 & 2,10 & 61,64 & 1,21 & 61,62 & 1,00 & 61,60 & 1,76 & 61,05 & 1,70 \\
\hline
\end{tabular}

${ }^{1}$ As médias, nos tratamentos com fogo e sem fogo e entre os anos de 1988 a 1994, nas suas respectivas profundidades, não diferem entre si pelo teste $t$. 
As curvas características de retenção de água (Fig. 1), nas profundidades de 0 a $5 \mathrm{~cm}, 5$ a $10 \mathrm{~cm} \mathrm{e}$ 10 a $20 \mathrm{~cm}$, mostram nas camadas do solo pequenas variações (de até cerca de $0,02 \mathrm{~m}^{3} \mathrm{~m}^{-3}$ ou $2 \mathrm{~L}$ de água) entre os tratamentos para as respectivas profundidades.
Comparando-se as curvas de retenção de água no solo nas profundidades estudadas, verifica-se que os teores de água retida diminuíram com a profundidade. Essas reduções acompanharam a diminuição, em profundidade, da densidade do solo, da mesoporosidade e da microporosidade. Essas diferenças po-

TABELA 4. Médias (X) e desvio-padrão (s) da macroporosidade $\left(\mathrm{m}^{3} \mathrm{~m}^{-3}\right)$, da mesoporosidade $\left(\mathrm{m}^{3} \mathrm{~m}^{-3}\right)$ e da microporosidade $\left(\mathrm{m}^{3} \mathrm{~m}^{-3}\right)$, em diferentes profundidades, nas parcelas submetidas ou não à queima com fogo, no período de 1988 a 1994 1.

\begin{tabular}{|c|c|c|c|c|c|c|c|c|c|c|c|}
\hline \multirow{2}{*}{$\begin{array}{l}\text { Trata- } \\
\text { mento }\end{array}$} & \multirow{2}{*}{$\begin{array}{l}\text { Profun- } \\
\text { didade } \\
(\mathrm{cm})\end{array}$} & \multicolumn{2}{|c|}{1988} & \multicolumn{2}{|c|}{1990} & \multicolumn{2}{|c|}{1992} & \multicolumn{2}{|c|}{1994} & \multicolumn{2}{|c|}{ Média } \\
\hline & & $\mathrm{X}$ & $\mathrm{s}$ & $\mathrm{X}$ & $\mathrm{s}$ & $\mathrm{X}$ & s & $\mathrm{X}$ & s & $\mathrm{X}$ & s \\
\hline & & & & & & croporos & $\mathrm{de}\left(\mathrm{m}^{3}\right.$ & & & & \\
\hline \multirow[t]{3}{*}{ Com fogo } & $0-5$ & 0,284 & 0,012 & 0,301 & 0,020 & 0,301 & 0,010 & 0,296 & 0,009 & 0,295 & 0,014 \\
\hline & $5-10$ & 0,310 & 0,009 & 0,303 & 0,014 & 0,315 & 0,004 & 0,308 & 0,010 & 0,309 & 0,009 \\
\hline & $10-20$ & 0,306 & 0,010 & 0,315 & 0,011 & 0,314 & 0,014 & 0,319 & 0,007 & 0,314 & 0,011 \\
\hline \multirow[t]{4}{*}{ Sem fogo } & $0-5$ & 0,275 & 0,017 & 0,286 & 0,003 & 0,286 & 0,005 & 0,285 & 0,006 & 0,283 & 0,010 \\
\hline & $5-10$ & 0,300 & 0,005 & 0,305 & 0,007 & 0,307 & 0,004 & 0,301 & 0,006 & 0,303 & 0,006 \\
\hline & $10-20$ & 0,306 & 0,003 & 0,311 & 0,003 & 0,312 & 0,003 & 0,316 & 0,004 & 0,311 & 0,013 \\
\hline & & \multicolumn{10}{|c|}{ Mesoporosidade $\left(\mathrm{m}^{3} \mathrm{~m}^{-3}\right)$} \\
\hline \multirow[t]{3}{*}{ Com fogo } & $0-5$ & 0,050 & 0,013 & 0,045 & 0,005 & 0,046 & 0,010 & 0,059 & 0,019 & 0,050 & 0,012 \\
\hline & $5-10$ & 0,037 & 0,005 & 0,036 & 0,004 & 0,036 & 0,004 & 0,049 & 0,005 & 0,040 & 0,007 \\
\hline & $10-20$ & 0,038 & 0,005 & 0,038 & 0,006 & 0,039 & 0,006 & 0,038 & 0,002 & 0,038 & 0,004 \\
\hline \multirow[t]{3}{*}{ Sem fogo } & $0-5$ & 0,051 & 0,015 & 0,050 & 0,004 & 0,049 & 0,005 & 0,051 & 0,009 & 0,050 & 0,008 \\
\hline & $5-10$ & 0,038 & 0,005 & 0,039 & 0,001 & 0,043 & 0,004 & 0,047 & 0,005 & 0,041 & 0,005 \\
\hline & $10-20$ & 0,041 & 0,011 & 0,039 & 0,003 & 0,036 & 0,001 & 0,039 & 0,002 & 0,039 & 0,005 \\
\hline & & \multicolumn{10}{|c|}{ Microporosidade $\left(\mathrm{m}^{3} \mathrm{~m}^{-3}\right)$} \\
\hline \multirow[t]{3}{*}{ Com fogo } & $0-5$ & 0,242 & 0,003 & 0,264 & 0,016 & 0,262 & 0,021 & 0,286 & 0,015 & $0,264^{*}$ & 0,021 \\
\hline & $5-10$ & 0,237 & 0,002 & 0,227 & 0,015 & 0,245 & 0,026 & 0,273 & 0,028 & $0,245^{*}$ & 0,025 \\
\hline & $10-20$ & 0,235 & 0,004 & 0,255 & 0,020 & 0,245 & 0,012 & 0,272 & 0,023 & 0,252 & 0,020 \\
\hline \multirow[t]{3}{*}{ Sem fogo } & $0-5$ & 0,266 & 0,026 & 0,282 & 0,005 & 0,295 & 0,009 & 0,284 & 0,022 & $0,282^{*}$ & 0,019 \\
\hline & $5-10$ & 0,259 & 0,007 & 0,256 & 0,006 & 0,282 & 0,005 & 0,271 & 0,025 & $0,267 *$ & 0,016 \\
\hline & $10-20$ & 0,246 & 0,008 & 0,266 & 0,008 & 0,268 & 0,010 & 0,262 & 0,020 & 0,260 & 0,013 \\
\hline
\end{tabular}

*As médias diferem entre si a 5\% de probabilidade pelo teste t, entre os tratamentos com fogo e sem fogo; as demais médias não diferem entre si.

TABELA 5. Médias (X) e desvio-padrão (s) dos teores de carbono orgânico ( $\left.\mathrm{g} \mathrm{kg}^{-1}\right)$, em diferentes profundidades, nas parcelas submetidas ou não à queima com fogo, no período de 1988 a $1994^{1}$.

\begin{tabular}{|c|c|c|c|c|c|c|c|c|c|c|c|}
\hline \multirow{2}{*}{$\begin{array}{l}\text { Trata- } \\
\text { mento }\end{array}$} & \multirow{2}{*}{$\begin{array}{l}\text { Profun- } \\
\text { didade } \\
(\mathrm{cm})\end{array}$} & \multicolumn{2}{|c|}{1988} & \multicolumn{2}{|c|}{1990} & \multicolumn{2}{|c|}{1992} & \multicolumn{2}{|c|}{1994} & \multicolumn{2}{|c|}{ Média } \\
\hline & & $X$ & $\mathrm{~s}$ & $X$ & $\mathrm{~s}$ & $X$ & $\mathrm{~s}$ & $\mathrm{X}$ & $\mathrm{s}$ & $X$ & $\mathrm{~s}$ \\
\hline \multirow[t]{3}{*}{ Com fogo } & $0-5$ & 18,29 & 3,68 & 18,34 & 0,74 & 20,66 & 2,60 & 19,79 & 1,04 & 19,27 & 2,25 \\
\hline & $5-10$ & 16,47 & 2,84 & 17,05 & 0,84 & 18,62 & 1,34 & 18,70 & 1,18 & 17,71 & 1,79 \\
\hline & $10-20$ & 13,53 & 1,65 & 14,53 & 1,01 & 15,76 & 0,86 & 16,53 & 1,44 & 15,09 & 1,62 \\
\hline \multirow[t]{3}{*}{ Sem fogo } & $0-5$ & 16,78 & 2,55 & 15,85 & 3,86 & 19,69 & 0,26 & 19,42 & 1,78 & 17,94 & 2,73 \\
\hline & $5-10$ & 15,72 & 2,00 & 15,12 & 3,42 & 18,33 & 0,17 & 18,51 & 1,89 & 16,92 & 2,46 \\
\hline & $10-20$ & 13,58 & 1,02 & 13,66 & 2,58 & 15,62 & 0,23 & 16,71 & 2,16 & 14,89 & 2,05 \\
\hline
\end{tabular}

${ }^{1}$ As médias, nos tratamentos com fogo e sem fogo e entre os anos de 1988 a 1994, nas suas respectivas profundidades, não diferem entre si pelo teste t. 
TABELA 6. Médias (X) e desvio-padrão (s) dos valores de argila (em $\mathrm{g} \mathrm{kg}^{-1}$ ) resultantes da análise de argila dispersa em água, no Latossolo Vermelho-Escuro, realizado em 1994, nas parcelas com fogo e sem fogo ${ }^{1}$.

\begin{tabular}{lccr}
\hline Tratamento & $\begin{array}{c}\text { Profundidade } \\
(\mathrm{cm})\end{array}$ & \multicolumn{2}{c}{ Argila dispersa em água } \\
\cline { 3 - 4 } & $0-5$ & $\mathrm{X}$ & $\mathrm{s}$ \\
\hline Com fogo & $0-10$ & 336,7 & 11,5 \\
& $10-20$ & 353,3 & 0,0 \\
& $0-5$ & 333,3 & 20,8 \\
\hline Sem fogo & $5-10$ & 340,0 & 5,8 \\
& $10-20$ & 363,3 & 20,0 \\
\hline
\end{tabular}

${ }^{1}$ As médias, nos tratamentos com fogo e sem fogo, nas suas respectivas profundidades, não diferem entre si pelo teste $t$.

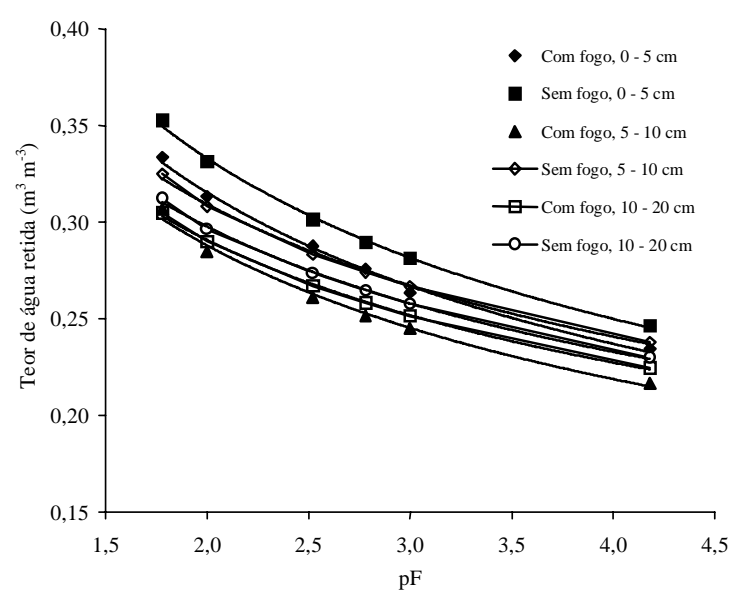

FIG. 1. Curvas de retenção de água nas tensões $\mathrm{pF}=1,78(0,006 \mathrm{MPa}), \mathrm{pF}=2,00(0,01 \mathrm{MPa})$, $\mathrm{pF}=2,52(0,033 \mathrm{MPa}), \mathrm{pF}=2,78(0,06 \mathrm{MPa})$, $\mathrm{pF}=3,00(0,1 \mathrm{MPa})$ e pF = 4,18 (1,5 MPa), nas profundidades de 0 a $5 \mathrm{~cm}, 5$ a $10 \mathrm{~cm}$ e 10 a $20 \mathrm{~cm}$, das parcelas com e sem fogo.

dem estar relacionadas às variações nos teores de argila e de carbono orgânico, não sendo observada relação pelo fato de a parcela ter sido, ou não, submetida ao fogo.

Na comparação das curvas de retenção de água, pode-se verificar também que elas são bastante semelhantes, indicando, assim, que não há ocorrência de características diferenciais entre as camadas do solo. Ao calcular as diferenças de quantidade de água retida entre as tensões $0,033 \mathrm{MPa}(\mathrm{pF}=2,52)$ e 1,5 $\mathrm{MPa}(\mathrm{pF}=4,18)$, respectivamente, a capacidade de campo e o ponto de murcha permanente (Hillel, 1980), constata-se que a retenção de água desse Latossolo Vermelho-Escuro é, de maneira geral, entre 0,04 e $0,05 \mathrm{~m}^{3} \mathrm{~m}^{-3}$, o que indica que esse solo, apesar de seu considerável teor de argila, apresenta capacidade de água disponível às plantas que pode ser classificada como baixa, de acordo com Curi et al. (1990).

As observações contidas neste artigo vem corroborar a hipótese de Meirelles (1990) sobre a influência de outros fatores do ambiente que devem interagir com o fogo, levando ao aumento ou diminuição da influência dele sobre a umidade do solo.

\section{CONCLUSÕES}

1. A queima bienal de vegetação de cerrado ralo, no período de seis anos, não altera significativamente a densidade do solo.

2. A queima bienal de vegetação de cerrado ralo, no período de seis anos, não altera significativamente a retenção de água no solo.

3. A queima bienal de vegetação de cerrado ralo, no período de seis anos, não altera significativamente o conteúdo de carbono orgânico no solo.

\section{REFERÊNCIAS}

ARAÚJO, Q.R.; FIGUEIREDO, M.S.; COSTA, L.M.; LOURES, E.G.; REGAZZI, A.J.; FONTES, L.E.F.; CASALI, V.W.D. Ação da queima e da percolação sobre propriedades químicas de um Latossolo Vermelho-Amarelo variação Una. Revista Ceres, Viçosa, v.41, n.237, p.537-558, 1994.

ARCHER, J.R.; SMITH, P.D. The relation between bulk density, available water capacity, and air capacity of soils. Journal of Soil Science, London, v.23, n.4, p.475-480, 1972.

ASSAD, M.L.R.C.L. Recursos biológicos: ocorrência e viabilidade. In: SIMPÓSIO SOBRE O CERRADO, 8., INTERNATIONAL SYMPOSIUM ON TROPICAL SAVANNAS, 1., 1996, Brasília. Anais / Proceedings. Planaltina, DF : Embrapa-CPAC, 1996. p.20-24. 
BANZATTO, D.A.; KRONKA, S. do N. Experimentação agrícola. Jaboticabal : FUNEP, 1992. 247p.

BUCHELE, F.A.; SILVA, J.A. da. Manual prático de irrigação por aspersão em sistemas convencionais. Florianópolis : EPAGRI, 1992. 81p. (EPAGRI. Boletim Técnico, 58).

CURI, N.; RESENDE, M.; SANTANA, D.P. Curso de engenharia da irrigação: terras para irrigação. Brasília : Associação Brasileira de Educação Agrícola Superior, 1990. 107p. Módulo 1.

EMBRAPA. Centro Nacional de Pesquisa de Solos (Rio de Janeiro, RJ). Manual de métodos de análises de solos. 2.ed. rev. Rio de Janeiro, 1997. 255p.

EMBRAPA. Serviço Nacional de Levantamento e Conservação de Solos (Rio de Janeiro, RJ). Levantamento e reconhecimento dos solos do Distrito $\mathrm{Fe}$ deral. Rio de Janeiro, 1978. 455p. (EmbrapaSNLCS. Boletim Técnico, 53)

FERREIRA, M.M. Física do solo. Lavras : ESAL/UFLAFAEPE, 1993. 71p.

FREITAS JÚNIOR, E. de; SILVA, E.M. da. Uso da centrífuga para determinação da curva de retenção de água do solo, em uma única operação. Pesquisa Agropecuária Brasileira, Brasília, v.19, n.11, p.1423-1428, nov. 1984.

FROST, P.; MEDINA, E.; MENAUT, J.C.; SOLBRIG, O.; SWIFT, M.; WALKER, B. Responses of savannas to stress and disturbance: a proposal for a collaborative program of research. Biology International IUBS Newsmagazine, Paris, n.10, p.1-82, 1986. Special Issue.

HERNANI, L.C.; SAKAI, E.; LOMBARDI NETO, F.; LEPSCH, I.F. Influência de métodos de limpeza de terreno sob floresta secundária em latossolo amarelo do Vale do Ribeira, SP. II. Perdas por erosão. Revista Brasileira de Ciência do Solo, Campinas, v.11, n.2, p.215-219, 1987.

HILLEL, D. Fundamentals of soil physics. New York : Academic, 1980. 413p.

LEITE, L.L. Densidade global e infiltração de água no solo em área de Cerrado submetida à queima controlada no DF, Brasil. In: MIRANDA, H.S.; SAITO, C.H.; DIAS, B.C.S. Impactos de queimadas em áreas de Cerrado e restinga. Brasília : UnB, 1996. p.31-36.
LLOYD, P.S. Effects of fire on a derbyshire grassland community. Ecology, Durham, v.53, n.5, p.915-920, 1972.

LUXMOORE, R.J. Micro, meso, and macroporosity of soil. Soil Science Society of America. Journal, Madison, v.45, n.3, p.671-672, May/June 1981

MACEDO, J.; BRYANT, R.B. Morphology, mineralogy, and genesis of a hydrosequence of oxisols in Brazil. Soil Science Society of America. Journal, Madison, v.51, n.3, p.690-698, May/June 1987.

MALLIK, A.V.; GIMINGHAM, C.H.; RAHMAN, A.A. Ecological effects of heather burning. I. Water infiltration, moisture retention and porosity of surface soil. Journal of Ecology, Oxford, v.72, n.3, p.767776, 1984

MEIRELLES, M.L. Efeito do fogo sobre a umidade do solo em área de campo sujo de cerrado. Ciência e Cultura, São Paulo, v.42, n.7, p.359-360, jul. 1990. Suplemento.

PIMENTEL-GOMES, F. A estatística moderna na pesquisa agropecuária. Piracicaba : Potafos, 1984. 160 .

REATTO, A.; CORREIA, J.R.; SPERA, S.T. Solos do bioma Cerrado: aspectos pedológicos. In: SANO, S.M.; ALMEIDA, S.P. de (Ed.). Cerrado: ambiente e flora. Planaltina, DF : Embrapa-CPAC, 1998. cap.3, p.47-86.

RAMOS, A.E.; ROSA, C.M.M. Impacto das queimadas. In: DIAS, B.F. de S. (Coord.). Alternativas de desenvolvimento dos Cerrados: manejo e conservação dos recursos naturais renováveis. Brasília : Fundação Pró-Natureza, 1996. p.34-38.

RIBEIRO, J.F.; WALTER, B.M.T. Fitofisionomias do bioma Cerrado. In: SANO, S.M.; ALMEIDA, S.P. de (Ed.). Cerrado: ambiente e flora. Planaltina, DF : Embrapa-CPAC, 1998. cap.3, p.89-166.

SANTOS, D.; BAHIA, V.G.; TEIXEIRA, W.G. Queimadas e erosão do solo. Informe Agropecuário, Belo Horizonte, v.16, n.176, p.62-68, 1992.

SHARROW, S.H.; WRIGHT, H.A. Effects of fire, ash, and litter on soil nitrate, temperature, moisture, and tobosagrass production in the rolling plains. Journal of Range Management, Denver, v.30, n.4, p.266270, 1977. 